\title{
Prognostic factors for ovarian metastases in colorectal cancer patients
}

\author{
Chao Chen ${ }^{1 \dagger}$, Da Wang ${ }^{1 \dagger}$, Xiaoxu Ge ${ }^{1,2}$, Jian Wang ${ }^{1}$, Yuhuai Huang ${ }^{1}$, Tianyi Ling ${ }^{1}$, Tian Jin ${ }^{1}$, Jinhua Yang 3 , \\ Fengping Wang $^{3}$, Weihong $\mathrm{Wu}^{3}$ and Lifeng Sun ${ }^{1 *}$ (D)
}

\begin{abstract}
Purpose: The aim of this study was to analyze prognostic factors for ovarian metastases (OM) in colorectal cancer (CRC) using data from a Chinese center. In addition, the study aimed at developing a new clinical scoring system for prognosis of OM of CRC patients after surgery.

Patients and methods: Data of CRC patients with OM were collected from a single Chinese institution ( $n=67)$. Kaplan-Meier analysis was used to evaluate cumulative survival of patients. Factors associated with prognosis of overall survival (OS) were explored using Cox's proportional hazard regression models. A scoring system to determine effectiveness of prognosis was developed.

Results: Median OS values for patients with or without surgery were 22 and 7 months, respectively. Size of $\mathrm{OM}$, number of $\mathrm{OM}$, peritoneal metastasis (PM), Peritoneal cancer index (PCI), and completeness of cytoreduction (CC) were associated with OS of patients through univariate analysis. Multivariate analysis using a Cox regression model showed that only CC was an independent predictor for OS. Three variables (the size of $\mathrm{OM}>15 \mathrm{~cm}, \mathrm{PCl} \geq 10$, and carcinoembryonic antigen (CEA) $>30 \mathrm{ng} / \mathrm{mL}$ ) assigned one point each were used to develop a risk score. The resulting score was used for prognosis of OS.

Conclusion: Surgical treatment of metastatic sites is effective and safe for CRC patients with OM. CC-O is recommended for improved prognosis. The scoring system developed in this study is effective for prediction of OS of patients after surgery.
\end{abstract}

Keywords: Colorectal cancer, Ovarian metastases, Prognosis factors, Cytoreductive surgery, Scoring system

\section{Introduction}

Colorectal cancer $(\mathrm{CRC})$ is the third most common cancer type in both males and females and the second leading cause of cancer-related death worldwide [1, 2]. Previous studies report that the incidence of ovarian metastasis $(\mathrm{OM})$ in female $\mathrm{CRC}$ and in female metastatic CRC are $1.6(\%) \sim 7.2(\%)$ and 5-10 (\%), respectively [3-6]. Approximately $0.6(\%) \sim 4.1(\%)$

\footnotetext{
* Correspondence: sunlifeng@zju.edu.cn

${ }^{\dagger}$ Chao Chen and Da Wang contributed equally to this work.

${ }^{1}$ Department of Colorectal Surgery and Oncology, Key Laboratory of Cancer Prevention and Intervention, Ministry of Education, the Second Affiliated

Hospital, Zhejiang University School of Medicine, 88 Jiefang Road, Hangzhou, Zhejiang Province 310009, People's Republic of China

Full list of author information is available at the end of the article
}

of patients with CRC develop synchronous OM, whereas 0.4 (\%) 5.1 (\%) of CRC patients develop metachronous OM during disease progression $[5,7,8]$. OM mostly affects young women and develops rapidly. Therefore, patients show symptoms in the later stage. Notably, OM are relatively chemoresistant compared with primary tumors and other metastases $[9,10]$. OM are considered end-stage disease and patients receiving palliative chemotherapy have extremely low survival rates (median OS of 10.0 months) [3, 11].

Cytoreductive surgery (CRS) is referred as a therapeutic strategy due to limitations associated with chemotherapy [9, 12-15]. CRS has revolutionized treatment of $\mathrm{OM}$ in CRC patients [16]. Patients achieve notable

(c) The Author(s). 2021 Open Access This article is licensed under a Creative Commons Attribution 4.0 International License, which permits use, sharing, adaptation, distribution and reproduction in any medium or format, as long as you give appropriate credit to the original author(s) and the source, provide a link to the Creative Commons licence, and indicate if changes were made. The images or other third party material in this article are included in the article's Creative Commons licence, unless indicated otherwise in a credit line to the material. If material is not included in the article's Creative Commons licence and your intended use is not permitted by statutory regulation or exceeds the permitted use, you will need to obtain permission directly from the copyright holder. To view a copy of this licence, visit http://creativecommons.org/licenses/by/4.0/ The Creative Commons Public Domain Dedication waiver (http://creativecommons.org/publicdomain/zero/1.0/) applies to the data made available in this article, unless otherwise stated in a credit line to the data. 
survival benefits (median OS of 36 to 43 months) after undergoing CRS compared with systemic chemotherapy [3]. However, to the best of our knowledge, recurrence, and distant metastasis still exist after detection, and currently, few studies report on the risk stratification and selection of patients who may benefit from surgical oophorectomy. Therefore, it is necessary to develop a clinical criterion for selecting patients to undergo surgical oophorectomy.

Data used in this study were retrieved from a single Chinese center. Data were used evaluate prognostic factors for CRC patients with OM. In addition, a clinical scoring system was developed using pre- and intraoperative factors to predict survival of CRC patients. The findings of this study will provide information and treatment strategies for clinicians and serve as a basis for further research.

\section{Material and methods}

\section{Ethics and patients}

CRC patients $(n=67)$ presenting with OM from January 2010 to July 2019 were included in this study. Details of surgical oophorectomy were analyzed for 54 patients because 13 patients did not undergo surgery or underwent surgery in a different hospital. The study was approved by the Institutional Review Board of the Second Affiliated Hospital of Zhejiang University School of Medicine. The study was conducted according to the Declaration of Helsinki, Fortaleza, Brazil, 2013. All patients included in the study provided signed informed consent.

\section{Inclusion and exclusion criteria}

Patients were enrolled into the study according to the following criteria: (1) diagnosis of CRC with synchronous or metachronous OM; (2) Eastern Cooperative Group (ECOG) performance status 0 or 1, and no extra- abdominal disease on radiological investigation; and (3) extent of $\mathrm{OM}$ evaluated either via contrast-enhanced computed tomography (CT) or magnetic resonance imaging of the ovaries, and treatment was discussed by the multidisciplinary cancer treatment team (MDT). Exclusion criteria were as follows: (1) follow-up time $<12$ months from the date of diagnosing OM and (2) extraabdominal metastasis.

\section{CRS/HIPEC}

Completeness of cytoreduction (CC) was classified as one of four grades (CC- $0,-1,-2$, and -3 ) based on the size of residual tumors after CRS. CRS was performed to remove all macroscopic OM or leave lesions $<2.5 \mathrm{~mm}$ (CC-0/1), which was considered optimal cytoreduction. Extent of disease was assessed using peritoneal cancer index (PCI) score, as described by Jacquet and Sugarbaker [17]. HIPEC was performed immediately after the abdomen was closed in the operating room. Mitomycin C (30 mg) or oxaliplatin (400 mg) was administered for $60 \mathrm{~min}$ at $43{ }^{\circ} \mathrm{C}$ in all cases. After postoperative recovery, patients received systemic chemotherapy for a maximum of 24 weeks.

\section{Clinical follow-up}

A follow-up was carried out for all patients in the outpatient unit approximately 2 weeks after treatment, and at least every 3 months for 2 years, then every 6 months after the first 2 years. Carcinoembryonic antigen (CEA), carbohydrate antigen 199 (CA199), and carbohydrate antigen 125 (CA125) markers, and CT scans of the abdomen, pelvis, and thorax, were assessed at each followup visit.

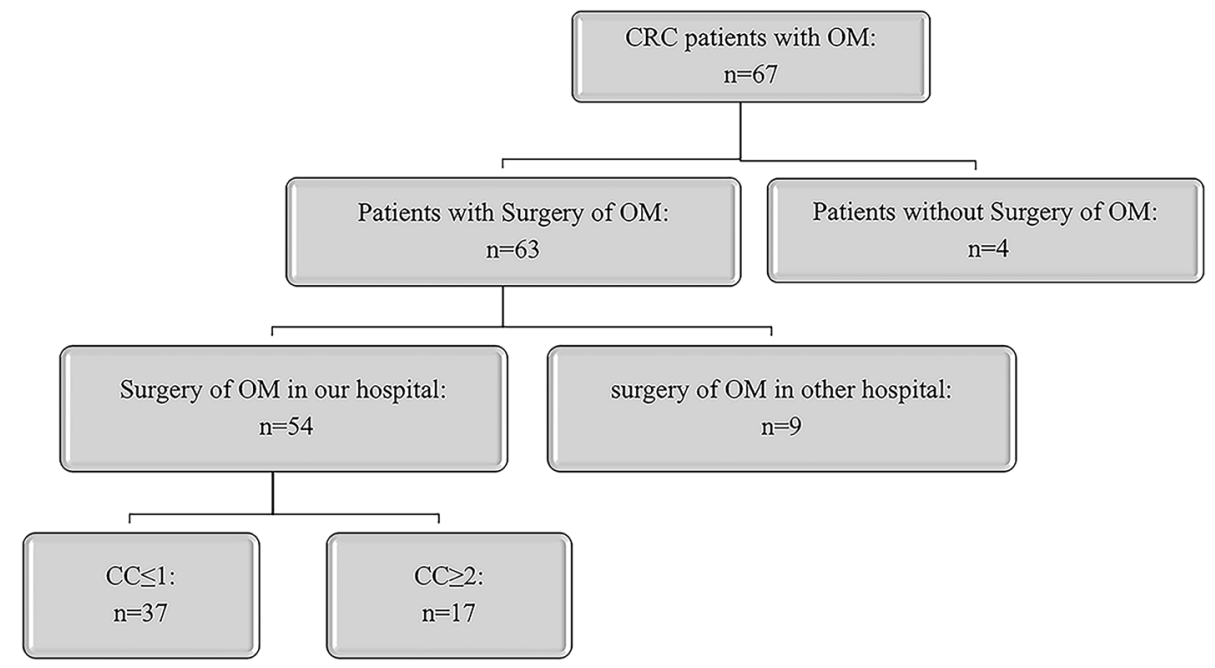

Fig. 1 A flowchart of patient included in this study 


\section{Statistical analysis}

Overall survival (OS) was defined as period between the date patients were diagnosed with $\mathrm{OM}$ to the last known date of follow-up or date of death. Cumulative survival was evaluated by Kaplan-Meier analysis. Differences in survival curves between groups of patients were assessed using the log-rank test. Multivariate analyses were performed using Cox's proportional hazard regression models to identify factors associated with OS. A twosided $\mathrm{P}$ value $<0.05$ was considered statistically significant. A new clinical scoring system was developed using pre- and intraoperative factors to predict survival of CRC patients. All analyses were performed in IBM SPSS Statistics for Windows, Version 25.0. Armonk, NY: IBM Corp.

\section{Results}

\section{Clinicopathologic features}

A total of 67 CRC patients diagnosed with OM between January 2010 and June 2019 in our cancer center were included in this study (Fig. 1). Mean patient age was 49.1 (21-90) years old and $73.1 \%$ of the patients were more than 60 years old. Simultaneous OM was found in $53.7 \%$ of patients. The most location of primary cancer in CRC patients with OM is left colon ( $\mathrm{n}=41,61.2 \%)$. Extra-ovarian metastasis occurred in $47(73.4 \%)$ patients and in 35 (54.7\%) cases with PM. Adenocarcinoma cancer accounted for $76.1 \%$ and patients diagnosed with $\mathrm{OM}$ in our center mainly presented with $\mathrm{T} 4$ and $\mathrm{N} 1$ stage tumors $(65.7 \%$ and $34.3 \%$, respectively). A total of 27 patients underwent initial surgery for primary tumor in a different center. Surgery for OM was not performed or performed in other hospital for 13 patients, so we analyzed details of surgical oophorectomy for 54 patients; therefore, surgery details were not available for these cases. Therefore, we analyzed surgery data for 54 patients who underwent surgery in our hospital. A total of 32 patients $(59.3 \%)$ presented with perineural invasion and 22 patients (40.7\%) presented with tumor deposits. Most cases (79.6\%) presented with lymph node invasion, and the number of lymph nodes invaded was $\geq 4$ in 19 patients $(35.2 \%)$. More than $50 \%$ patients presented with $\mathrm{PCI} \leq 10$ and underwent CC-0/1 in our center. Demographic and histologic data of patients are summarized in Table 1.

\section{Survival outcomes}

Median follow-up time was 68 (range, 1 to 85) months from the date of OM diagnosis. Median OS for all patients was 22 months, with overall 1- and 3-year survival rates of $66.7 \%$ and $30.4 \%$, respectively. A total of 4 patients rejected surgery after OM diagnosis. Median OS for the 4 patients was 7 months compared with 22 months of patients who underwent CRS (Fig. 2).
Analysis of predictors using Kaplan-Meier method showed that size of $\mathrm{OM}(\mathrm{P}=0.018)$, presence of $\mathrm{PM}(\mathrm{P}=$ 0.016), PCI $(\mathrm{P}=0.003)$, and $\mathrm{CC}$ score $(\mathrm{P}<0.001)$ were significantly associated with OS (Table 2 ). However, vascular invasion, perineural invasion, CEA, CA125, or the number of lymph node invasion were not correlated with survival time. In addition, demographic and histologic data, including age, $\mathrm{T}$ stage, $\mathrm{N}$ stage, grade, pathological subtype, and primary cancer site, were not significantly correlated with survival time (Supplement Table 1). Factors with $\mathrm{P}$ value less 0.1 were used for multivariable analysis, and only incomplete cytoreduction was identified as an independent predictor for poor OS (CC >1; HR, 3.782, 95\% CI, 1.873 to 7.637; P <0.001) (Table 2, Fig. 3).

\section{A new clinical risk score for selecting suitable OM}

A new clinical risk score was developed using significant indicators for OS in Kaplan-Meier method including PCI and size of OM. CEA which is important for CRC was also included. Although progression of disease at the level of CC was an independent predictor of prognosis as shown by multivariate analysis, not all patients received surgery. Furthermore, addition of this factor into the risk score model did not improve its prognostic value; therefore, it was omitted from the final model. The score for the corresponding indicators HR value was rounded up to the integer value.

Clinical risk score of all patients was calculated using complete data. The new clinical risk score in patients was calculated with the actual distribution from 0 to 7 points and a median of 3 points and a mode of 3 points (Fig. 4A). Patients were divided into $<3$ groups and acuity grouping for subsequent analysis using cut-off value of 3 points (median). A score $<3$ patients resulted in a high CC-0 ratio (88.2\%), and most patients with a score $\geq 3$ points did not reach tumor removal stage (Fig. 4B). A high score was positively correlated with poor overall survival. Patients who scored $<3$ (low risk) had 1-, 3-, and 5 -year survival of $76.5 \%, 44.6 \%$, and $37.2 \%$, respectively, and median survival of 36 months. Patients who scored $\geq 3$ (high risk) had a 3 -year survival of $16.5 \%$ with no survivors beyond 5 years and median survival of 12 months (Fig. 4C).

\section{Discussion}

Previous studies have explored factors associated with prognosis of CRC patients with OM. However, this is the first study to develop a new clinical risk score to help in preoperative or intraoperative decision making. OM affects young women, develops rapidly, and is relatively chemoresistant; therefore, there is a need to develop effective treatment of OM patients [9]. Previous studies have reported controversial results on CRS for CRC 
Table 1 Demographic characteristics of patients

\begin{tabular}{|c|c|c|c|}
\hline \multicolumn{2}{|l|}{ All patients $(n=67)$} & \multicolumn{2}{|c|}{ Patients who underwent surgery in our center $(n=54)$} \\
\hline Variables & Value, N (\%) & Variables & Value, $\mathrm{N}(\%)$ \\
\hline Age (year) & & HIPEC & \\
\hline$\geq 60$ & $49(73.1 \%)$ & No & $32(59.3 \%)$ \\
\hline$<60$ & $18(26.9 \%)$ & Yes & $22(40.7 \%)$ \\
\hline Primary cancer & & Tumor deposits & \\
\hline Left colon cancer & $41(61.2 \%)$ & None & $29(53.7 \%)$ \\
\hline Right colon cancer & $24(35.8 \%)$ & Present & $10(18.5 \%)$ \\
\hline Unknown & $2(3.0 \%)$ & Unknown & $5(9.3 \%)$ \\
\hline Pathological type & & Primary tumor size & \\
\hline Adenocarcinoma & $51(76.1 \%)$ & $<5 \mathrm{~cm}$ & $29(53.7 \%)$ \\
\hline \multirow[t]{2}{*}{ Non-adenocarcinoma } & $16(23.9 \%)$ & $\geq 5 \mathrm{~cm}$ & $14(35.9 \%)$ \\
\hline & & Unknown & $11(20.4 \%)$ \\
\hline Grade & & Perineural invasion & \\
\hline Grade I & $6(9.0 \%)$ & None & $17(31.5 \%)$ \\
\hline Grade II & $40(59.7 \%)$ & Present & $30(55.6 \%)$ \\
\hline Grade III & $18(26.9 \%)$ & Unknown & $7(13.0 \%)$ \\
\hline Unknown & $3(4.5 \%)$ & & \\
\hline T stage & & Scope Reg LN Sur & \\
\hline T0-3 & $14(20.9 \%)$ & None & $13(24.1 \%)$ \\
\hline T4 & $44(65.7 \%)$ & Present & $36(66.7 \%)$ \\
\hline $\mathrm{Tx}$ & $9(13.4 \%)$ & Unknown & $5(9.3 \%)$ \\
\hline $\mathrm{N}$ stage & & Scope Reg LN Sur (Number) & \\
\hline NO & $15(22.4 \%)$ & $<4$ & $32(59.3 \%)$ \\
\hline N1 & $23(34.3 \%)$ & $\geq 4$ & $17(31.5 \%(\%))$ \\
\hline N2 & $19(28.4 \%)$ & Unknown & $5(9.3 \%)$ \\
\hline$N x$ & $10(14.9 \%)$ & & \\
\hline Primary tumor size & & Metastatic tumor size & \\
\hline$<5 \mathrm{~cm}$ & $30(44.8 \%)$ & $\leq 15 \mathrm{~cm}$ & $37(68.5 \%)$ \\
\hline$\geq 5 \mathrm{~cm}$ & $15(22.4 \%)$ & $>15 \mathrm{~cm}$ & $14(25.9 \%)$ \\
\hline Unknown & $22(32.8 \%)$ & Unknown & $3(5.6 \%)$ \\
\hline Time of OM & & Time of OM & \\
\hline Synchronous & $36(53.7 \%)$ & Synchronous & $31(57.4 \%)$ \\
\hline \multirow[t]{12}{*}{ Metachronous } & $31(46.3 \%)$ & Metachronous & $23(42.6 \%)$ \\
\hline & & Number of OM & \\
\hline & & Unilateral & $21(38.9 \%)$ \\
\hline & & Bilateral & $31(57.4 \%)$ \\
\hline & & Unknown & $2(3.7 \%)$ \\
\hline & & Parenchymatous organ metastasis & \\
\hline & & None & $18(33.3 \%)$ \\
\hline & & $\mathrm{OM}+\mathrm{PM}$ & $14(25.9 \%)$ \\
\hline & & $\mathrm{OM}+\mathrm{PM}+\mathrm{others}$ & $17(31.5 \%)$ \\
\hline & & OM+others & $5(9.3 \%)$ \\
\hline & & Peritoneal metastasis & \\
\hline & & No & $32(59.3 \%)$ \\
\hline
\end{tabular}


Table 1 Demographic characteristics of patients (Continued)

\begin{tabular}{|c|c|c|c|}
\hline \multicolumn{2}{|c|}{ All patients $(n=67)$} & \multicolumn{2}{|c|}{ Patients who underwent surgery in our center $(n=54)$} \\
\hline Variables & Value, N (\%) & Variables & Value, $\mathbf{N}(\%)$ \\
\hline & & Yes & $22(40.7 \%)$ \\
\hline & & CA125 & \\
\hline & & $\leq 40 \mathrm{kU} / \mathrm{L}$ & $20(37.0 \%)$ \\
\hline & & $>40 \mathrm{kU} / \mathrm{L}$ & $25(46.3 \%)$ \\
\hline & & Unknown & $9(16.7 \%)$ \\
\hline & & CEA & \\
\hline & & $\leq 30 \mathrm{mg} / \mathrm{L}$ & $32(59.3 \%)$ \\
\hline & & $>30 \mathrm{mg} / \mathrm{L}$ & $15(27.8 \%)$ \\
\hline & & Unknown & $7(13.0 \%)$ \\
\hline & & CA199 & \\
\hline & & $\leq 60 \mathrm{kU} / \mathrm{L}$ & $31(57.4 \%)$ \\
\hline & & $>60 \mathrm{kU} / \mathrm{L}$ & $16(29.6 \%)$ \\
\hline & & Unknown & $7(13.0 \%)$ \\
\hline & & $\mathrm{PCl}$ & \\
\hline & & $\leq 10$ & $29(53.7 \%)$ \\
\hline & & $>10$ & $25(46.3 \%)$ \\
\hline & & $\mathrm{CC}$ & \\
\hline & & $0-1$ & $37(68.5 \%)$ \\
\hline & & $>1$ & 17 (31.5\%) \\
\hline
\end{tabular}

patients with OM. Some surgeons recommend CRS as it improves CRC patient survival [16, 18-20]. However, some studies report that CRS approach is ineffective [21, 22]. In this study, median OS for CRC patients with OM group who underwent surgery was 22 months, compared with median OS of 10 months for patients receiving palliative treatment reported by Lee et al. [11]. Previous studies report that CRS affects long-term prognosis and recurrence of patients with CRC [23-29] and similar results were reported in our study. CRC patients with OM who achieved CC-0 showed a median OS of 36 months, whereas patients who did not achieve CC-0 showed a median OS of 3 months. Multivariate analysis showed that incomplete cytoreduction is an independent risk factor for OS. However, HIPEC was not associated with OS of CRC patients in our study, which can be attributed to the small sample size. The results of the current study show that CRS should be performed on CRC patients as it is safe, feasible, and effective for treatment of diverse advanced tumors.

However, some researches showed the influence of ovariectomy for female [30-32]. Ovariectomy will cause menopause in young patients, which makes a sudden perimenopausal syndrome, and the more severe symptoms than natural [30]. Besides, a cohort study in Britain reported that early menopause is a risk of ischemic stroke (early menopause vs natural menopause, $\mathrm{HR}=1.5$, 95\% CI 1. 01 2. 25) [31]. According to Mayo Clinic Oophorectomy and Aging Cohort Study, early menopause caused by surgery is associated with osteoporosis, worse neurocognitive performance, and symptoms of depression or anxiety [32, 33].

The findings of this study show that complete resection of ovarian metastasis is positively correlated with a better prognosis. However, CRC patients with OM to undergo surgery should be selected carefully. Preoperative assessment of suitable patients for aggressive treatment mode can reduce switching operation rate, incomplete tumor surgery rate, and perioperative mortality. Currently, there is no unified standard but some considerations include informed consent and will of patient, ECOG $<2$, no serious complications, acceptable quality of life, asymptomatic, lack of tumor progression during chemotherapy, absence of extravasation, resectable liver metastases $<=3$, intestinal stenosis $<=1$, no widespread intestinal disease, no biliary or ureteral obstruction, stomach liver toughening with involvement $<5 \mathrm{~cm}$, no mesenteric root or pancreatic infiltration, possibility of completing $\mathrm{CC} 0-1$, and PCI < 20; however, prognosis of patients are different. Several prognostic scoring system have been reported as references for CRC patients with PM, including Colorectal Peritoneal 


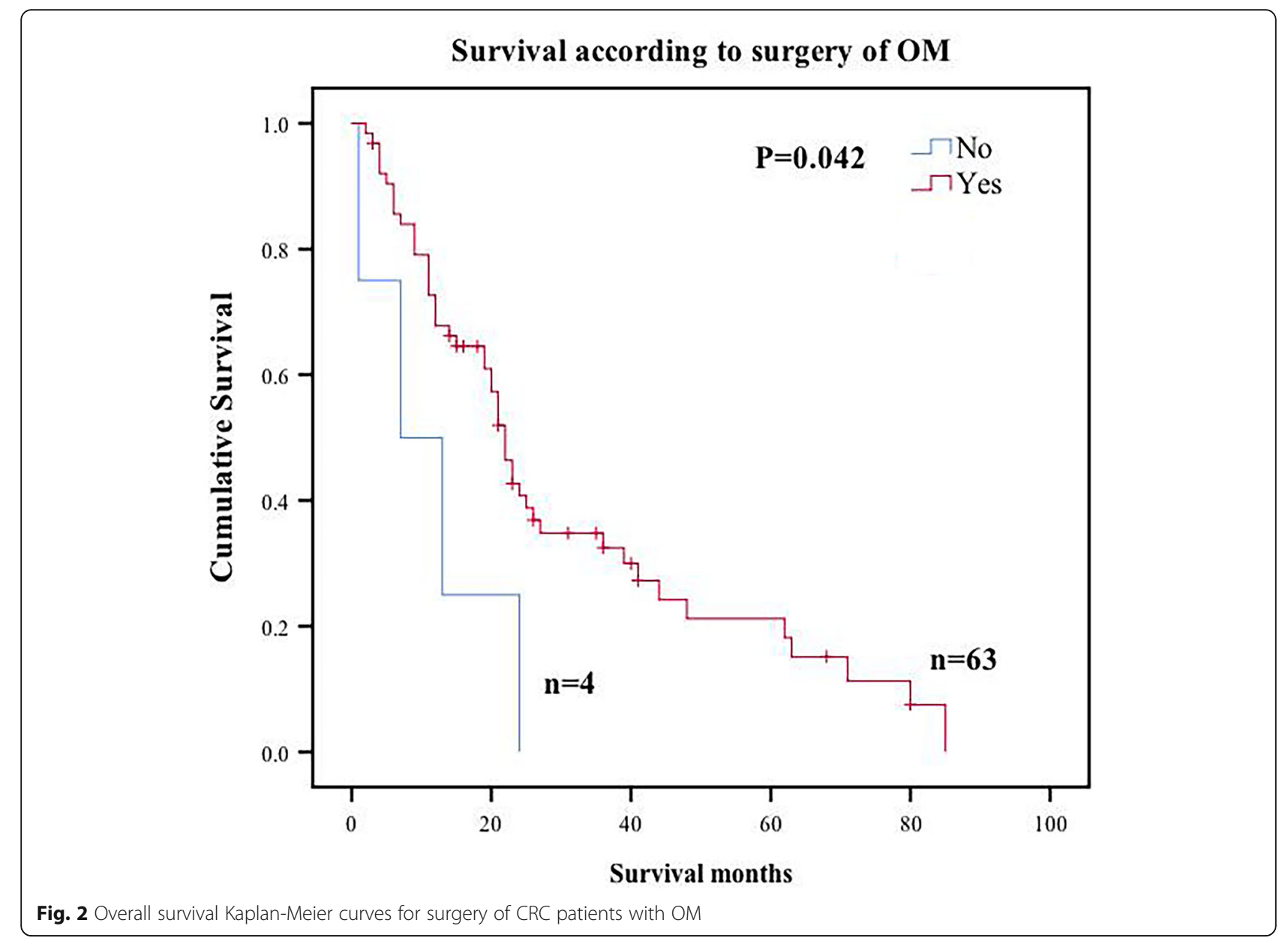

Score [34], Peritoneal Surface Disease Severity Score (PSDSS) [35], and Colorectal Peritoneal Metastases Prognostic Surgical Score [36, 37]. Pelz et al. developed a PSDS $\mathrm{S}$ based on clinical symptoms, PCI, and histology to serve as a prognostic tool for overall survival for clinicians and researchers. Simkens et al. evaluated peritoneal surface disease PSDSS and suggested COMPASS, including age, PCI, locoregional lymph node status, and signet ring cell histology. However, no other single factor examined reliably differentiated suitable patients to undergo surgery from CRC patients with OM who met an early demise. Therefore, we sought to develop a scoring system using multiple factors to provide information on pre-operative or intra-operative decision making. The alternative system uses 3 variables including $\mathrm{PCI}$, size of $\mathrm{OM}$, and CEA > $30 \mathrm{ng} / \mathrm{mL}$. In order to maximize clinical utility, only variables known preoperatively and/or intraoperatively were included. Therefore, although completeness of OM resection was prognostic factor for survival as shown by multivariate analysis, $\mathrm{CC}$ was not used in building our predictive model. All three factors in the final scoring model were weighted based on comparable hazard ratios
(2.295, 2.536, and 0.899 for PCI, size of OM and CEA > $30 \mathrm{ng} / \mathrm{mL}$, respectively).

A group of patients (risk score $\geq 3$ ) who performed poorly after resection were identified using this proposed risk scoring system. These outcomes were consistent with modern chemotherapy outcomes (median OS=12). The findings show that higher score is correlated with poor prognosis. High clinical risk score was associated with significant decrease in proportion of $\mathrm{CC}-0$ patients, whereas the proportion of $\mathrm{CC}-3$ or $\mathrm{CC}-4$ patients was significantly increased. These findings imply that $\mathrm{CC}-3$ or CC-4 patients should not undergo resection. In contrast, patients with $<3$ points showed comparable survival to patients with surgery.

Prognostic factors were analyzed and a new clinical risk score for CRC patients with OM was developed using data from our center; however, our study had some limitations. First, this was a retrospective study; therefore, it had potential bias. Second, we used a sample size comprising $67 \mathrm{CRC}$ patients with OM. These limitations could be ameliorated by recruitment of more patients for inclusion in a future prospective study. 
Table 2 Univariate analysis and multivariate analysis of factors associated with OS using a Cox regression model for patients underwent CRS in our center. Statistically significant $P$ values are presented in bold-italics. P values that are not statistically significant are presented in in italics

\begin{tabular}{|c|c|c|c|c|}
\hline \multirow[t]{2}{*}{ Variables } & \multicolumn{2}{|l|}{ Univariate analysis } & \multicolumn{2}{|c|}{ Multivariate analysis } \\
\hline & $95 \% \mathrm{Cl}$ & $P$ value & $95 \% \mathrm{Cl}$ & $P$ value \\
\hline \multicolumn{5}{|c|}{ Tumor deposits } \\
\hline \multicolumn{5}{|l|}{ None } \\
\hline Present & $1.131(0.589-2.172)$ & $P=0.711$ & & \\
\hline Unknown & $0.355(0.081-1.556)$ & $P=0.169$ & & \\
\hline \multicolumn{5}{|c|}{ Perineural invasion } \\
\hline \multicolumn{5}{|l|}{ None } \\
\hline Present & $1.233(0.613-2.480)$ & $P=0.556$ & & \\
\hline Unknown & $0.375(0.114-1.234)$ & $P=0.107$ & & \\
\hline \multicolumn{5}{|c|}{ Scope Reg LN Sur } \\
\hline \multicolumn{5}{|l|}{ None } \\
\hline Present & $1.785(0.781-4.079)$ & $P=0.169$ & & \\
\hline Unknown & $0.515(0.105-2.535)$ & $P=0.414$ & & \\
\hline \multicolumn{5}{|c|}{ Scope Reg LN Sur (Number) } \\
\hline \multicolumn{5}{|l|}{$<4$} \\
\hline$\geq 4$ & $1.536(0.792-2.978)$ & $P=0.204$ & & \\
\hline Unknown & $0.394(0.090-1.724)$ & $P=0.216$ & & \\
\hline \multicolumn{5}{|l|}{ HIPEC } \\
\hline \multicolumn{5}{|l|}{ No } \\
\hline Yes & $0.868(0.479-1.573)$ & $P=0.641$ & & \\
\hline \multicolumn{5}{|c|}{ Metastatic tumor size } \\
\hline \multicolumn{5}{|l|}{$\leq 15 \mathrm{~cm}$} \\
\hline$>15 \mathrm{~cm}$ & $2.536(1.174-5.480)$ & $P=0.018$ & & \\
\hline Unknown & $0.711(0.167-3.024)$ & $P=0.644$ & & \\
\hline \multicolumn{5}{|c|}{ Number of OM } \\
\hline \multicolumn{5}{|l|}{ Unilateral } \\
\hline Bilateral & $1.956(0.965-3.967)$ & $P=0.063$ & & \\
\hline Unknown & $1.779(0.394-8.021)$ & $P=0.454$ & & \\
\hline \multicolumn{5}{|l|}{ PM } \\
\hline \multicolumn{5}{|l|}{ No } \\
\hline Yes & $2.295(1.170-4.503)$ & $P=0.016$ & & \\
\hline \multicolumn{5}{|l|}{$\mathrm{PCl}$} \\
\hline \multicolumn{5}{|l|}{$\leq 10$} \\
\hline$>10$ & $2.807(1.421-5.544)$ & $P=0.003$ & & \\
\hline \multicolumn{5}{|l|}{ CA125 } \\
\hline \multicolumn{5}{|l|}{$\leq 40 \mathrm{kU} / \mathrm{L}$} \\
\hline$>40 \mathrm{kU} / \mathrm{L}$ & $1.212(0.603-2.436)$ & $P=0.589$ & & \\
\hline unknown & $1.012(0.411-2.491)$ & $P=0.979$ & & \\
\hline \multicolumn{5}{|l|}{ CEA } \\
\hline \multicolumn{5}{|l|}{$\leq 30 \mathrm{mg} / \mathrm{L}$} \\
\hline$>30$ mg/L & $0.899(0.437-1.852)$ & $P=0.773$ & & \\
\hline unknown & $0.728(0.276-1.920)$ & $P=0.521$ & & \\
\hline CA199 & & & & \\
\hline
\end{tabular}


Table 2 Univariate analysis and multivariate analysis of factors associated with OS using a Cox regression model for patients underwent CRS in our center. Statistically significant $P$ values are presented in bold-italics. P values that are not statistically significant are presented in in italics (Continued)

\begin{tabular}{|c|c|c|c|c|}
\hline \multirow[t]{2}{*}{ Variables } & \multicolumn{2}{|l|}{ Univariate analysis } & \multicolumn{2}{|l|}{ Multivariate analysis } \\
\hline & $95 \% \mathrm{Cl}$ & $P$ value & $95 \% \mathrm{Cl}$ & $P$ value \\
\hline \multicolumn{5}{|l|}{$\leq 60 \mathrm{kU} / \mathrm{L}$} \\
\hline$>60 \mathrm{kU} / \mathrm{L}$ & $0.837(0.397-1.765)$ & $P=0.641$ & & \\
\hline unknown & $0.713(0.271-1.876)$ & $P=0.494$ & & \\
\hline \multicolumn{5}{|l|}{ CC } \\
\hline \multicolumn{5}{|l|}{0} \\
\hline 1 & $7.412(2.170-25.317)$ & $P=0.001$ & $7.412(2.170-25.317)$ & $P=0.001$ \\
\hline 2 & $4.827(2.235-10.422)$ & $P<0.001$ & $4.827(2.235-10.422)$ & $P<0.001$ \\
\hline 3 & $143.854(8.430-2454.725)$ & $P=0.001$ & $143.854(8.430-2454.725)$ & $P=0.001$ \\
\hline \multicolumn{5}{|l|}{ CC } \\
\hline \multicolumn{5}{|l|}{$0-1$} \\
\hline$>1$ & $3.782(1.873-7.637)$ & $P<0.001$ & $3.782(1.873-7.637)$ & $P<0.001$ \\
\hline
\end{tabular}

Abbreviations: $N$, number; $C E A$, carcinoembryonic antigen; Scope Reg $L N$ Sur, regional lymph node surgery in surgery; OS, overall survival; $H R$, hazard ratio; $C l$, confidence interval

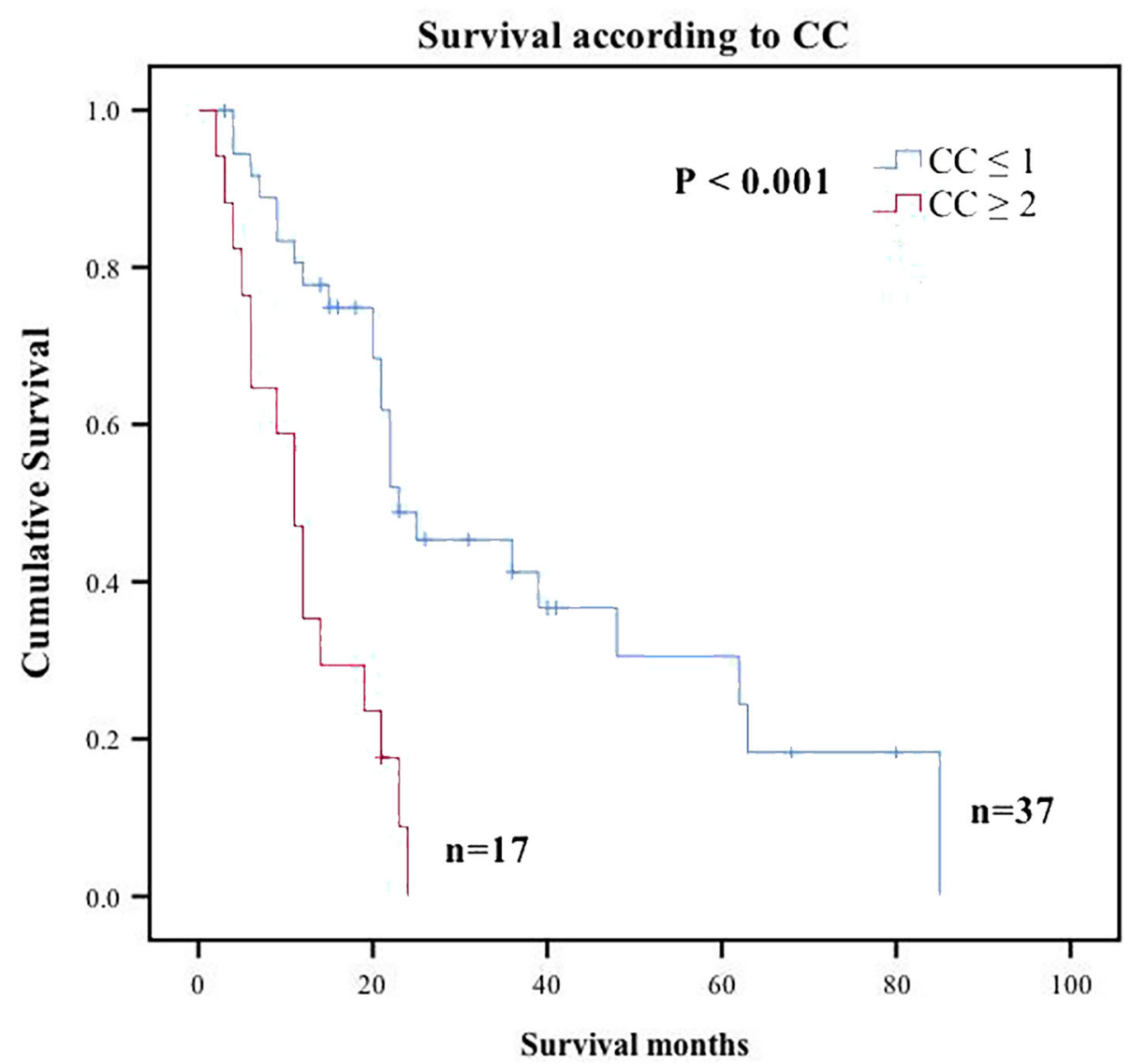

Fig. 3 Overall survival Kaplan-Meier curves for significant prognostic variables for CRC patients with OM who underwent surgery. CC, completeness of cytoreduction 


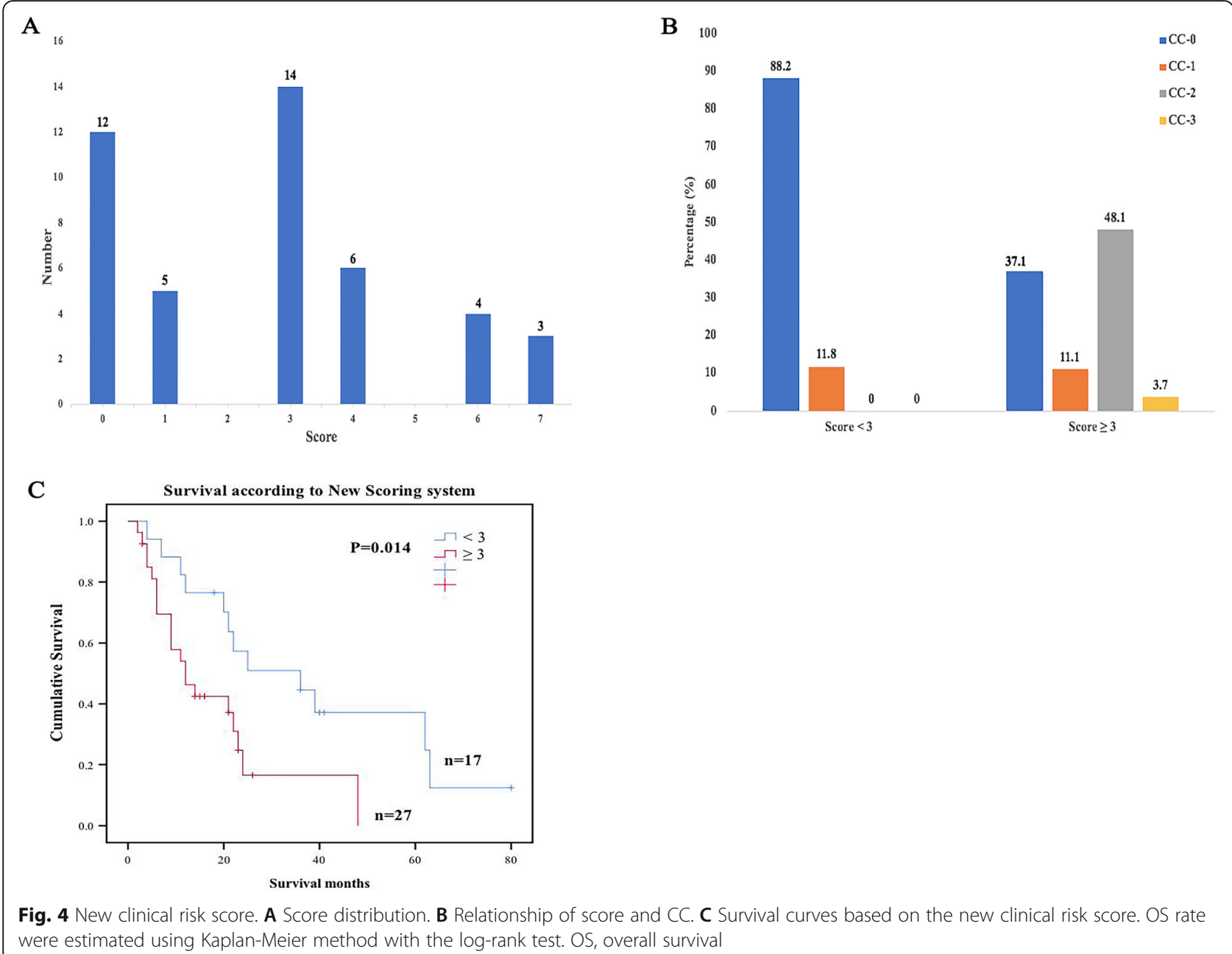

Studies including more samples should be carried out to assess effectiveness of treatments and explore effective prognostic factors for CRC patients with OM.

\section{Conclusion}

In summary, surgery is an effective and safe treatment approach for CRC patients with OM. In addition, surgery of the metastatic site should be recommended for CRC patients with OM to achieve CC- 0 . OM should not be considered an absolute contraindication to curative resection; however, appropriate selection is important. The proposed scoring system provides a basis for identification of a subset of patients who do not benefit from resection.

\section{Abbreviations}

CRC: Colorectal cancer; PM: Peritoneal metastasis; OM: Ovarian metastasis; OS: Overall survival; PCI: Peritoneal cancer index; CRS/HIPEC: Cytoreductive surgery combined with hyperthermic intraperitoneal chemotherapy;

CEA: Carcinoembryonic antigen; Reg LN Sur: Regional lymph node surgery in surgery; PNI: Perineural invasion

\section{Supplementary Information}

The online version contains supplementary material available at https://doi. org/10.1186/s12957-021-02305-3.

Additional file 1: Supplemental Table 1. Univariate analysis and multivariate analysis of factors associated with OS with a cox regression model in all patients. OS, overall survival; $\mathrm{HR}$, Hazard Ratio; Cl, Confidence Interval; Statistically significant P values are presented in bold-italics. P values that are not statistically significant are presented in italics.

\section{Acknowledgements}

Our special acknowledgments to Mr. Bo Liu for helping us with the editing.

\section{Authors' contributions}

Study concepts: Lifeng Sun, Chao Chen, and Da Wang; data acquisition: Yuhuai Huang, Xiaoxu Ge, Jinhua Yang, Fengping Wang, and Tian Jin; manuscript preparation: Chao Chen, Xiaoxu Ge, and Weihong Wu; manuscript editing: Jian Wang and Linian Ling; Manuscript review: Lifeng Sun. The authors read and approved the final manuscript.

\section{Funding}

The study was funded by National Natural Science Foundation of China (No. 81472819, No. 81672342), the Zhejiang Provincial Key R\&D Program of China (No. 2019C03018), the Zhejiang Provincial Natural Science Foundation of China (No. LY20H160038, LQ17H160008), and the Fundamental Research Funds for the Central Universities (No. 2019QNA7028, No. 2019FZJD009). 


\section{Availability of data and materials}

All data generated or analyzed during this study are included in this published article.

\section{Declarations}

\section{Ethics approval and consent to participate}

This study was reviewed and approved by Institutional Review Board of the Second Affiliated Hospital of Zhejiang University School of Medicine. Informed consents were obtained from all participants in the study.

\section{Consent for publication}

Not applicable.

\section{Competing interests}

Authors declare that they have no conflicts of interest.

\section{Author details}

'Department of Colorectal Surgery and Oncology, Key Laboratory of Cancer Prevention and Intervention, Ministry of Education, the Second Affiliated Hospital, Zhejiang University School of Medicine, 88 Jiefang Road, Hangzhou, Zhejiang Province 310009, People's Republic of China. ${ }^{2}$ Department of Cancer Institute, the Second Affiliated Hospital, Zhejiang University School of Medicine, Hangzhou, Zhejiang Province, People's Republic of China. ${ }^{3}$ Department of Gastrointestinal Surgery, Changxing County People's Hospital, Huzhou, Zhejiang Province, People's Republic of China.

Received: 6 March 2021 Accepted: 19 June 2021

\section{Published online: 20 July 2021}

\section{References}

1. Siegel RL, Miller KD, Jemal A. Cancer statistics, 2020. CA Cancer J Clin. 2020; 70(1):7-30. https://doi.org/10.3322/caac.21590.

2. Bray F, Ferlay J, Soerjomataram I, Siegel R, Torre L, Jemal A. Global Cancer Statistics 2018: GLof incidence and mortality world in 185 countries. CA Cancer J Clin Anticancer Res. 2018;55:78-108.

3. Ganesh K, Shah RH, Vakiani E, Nash GM, Skottowe HP, Yaeger R, et al. Clinical and genetic determinants of ovarian metastases from colorectal cancer. Cancer. 2017;123(7):1134-43. https://doi.org/10.1002/cncr.30424.

4. Evers DJ, Verwaal VJ. Indication for oophorectomy during cytoreduction for intraperitoneal metastatic spread of colorectal or appendiceal origin. $\mathrm{Br}$ J Surg. 2011;98:287-92.

5. Segelman J, Flöter-Rådestad A, Hellborg H, Sjövall A, Martling A. Epidemiology and prognosis of ovarian metastases in colorectal cancer. $\mathrm{Br} \mathrm{J}$ Surg. 2010;97(11):1704-9. https://doi.org/10.1002/bjs.7196.

6. Kajiyama H, Suzuki S, Utsumi F, Nishino K, Niimi K, Mizuno M, et al. Epidemiological overview of metastatic ovarian carcinoma: long-term experience of TOTSG database. Nagoya J Med Sci. 2019;81:193.

7. Byun JH, Ahn JB, Kim SY, Kang JH, Zang DY, Kang SY, et al. The impact of primary tumor location in patients with metastatic colorectal cancer: a Korean Cancer Study Group CO12-04 study. Korean J Intern Med. 2019;34(1): 165-77. https://doi.org/10.3904/kjim.2016.348.

8. Fujiwara A, Noura S, Ohue M, Shingai T, Yamada T, Miyashiro I, et al. Significance of the resection of ovarian metastasis from colorectal cancers. J Surg Oncol. 2010;102(6):582-7. https://doi.org/10.1002/jso.21675.

9. Sekine K, Hamaguchi T, Shoji H, Takashima A, Honma Y, Iwasa S, et al. Retrospective analyses of systemic chemotherapy and cytoreductive surgery for patients with ovarian metastases from colorectal cancer: a single-center experience. Oncology. 2018;95(4):220-8. https://doi.org/10.1159/000489665.

10. Ojo J, De Silva S, Han E, Lin P, Wakabayashi M, Nelson R, et al. Krukenberg tumors from colorectal cancer: presentation, treatment and outcomes. Am Surg. 2011;77(10):1381-5. https://doi.org/10.1177/000313481107701025.

11. Lee SJ, Lee J, Lim HY, Kang WK, Choi CH, Lee JW, et al. Survival benefit from ovarian metastatectomy in colorectal cancer patients with ovarian metastasis: a retrospective analysis. Cancer Chemother Pharmacol. 2010; 66(2):229-35. https://doi.org/10.1007/s00280-009-1150-2.

12. Bignell MB, Mehta AM, Alves S, Chandrakumaran K, Dayal SP, Mohamed F, et al. Impact of ovarian metastases on survival in patients treated with cytoreductive surgery and hyperthermic intraperitoneal chemotherapy for peritoneal malignancy originating from appendiceal and colorectal cancer Color Dis. 2018;20(8):704-10. https://doi.org/10.1111/codi.14057.
13. Kim WY, Kim TJ, Kim SE, Lee JW, Lee JH, Kim BG, et al. The role of cytoreductive surgery for non-genital tract metastatic tumors to the ovaries Eur J Obstet Gynecol Reprod Biol. 2010;149(1):97-101. https://doi.org/10.101 6/j.ejogrb.2009.11.011.

14. Sudo M, Furuya S, Shimizu H, Nakata Y, lino H, Shiraishi K, et al. Long-term outcomes after surgical resection in patients with stage IV colorectal cancer: a retrospective study of 129 patients at a single institution. World J Surg Oncol. 2019;17(1):56. https://doi.org/10.1186/s12957-019-1599-3.

15. Ambe PC, Kankam J, Zarras K. Peritoneal spillage is not an issue in patients undergoing minimally invasive surgery for colorectal cancer. World J Surg Oncol. 2020;18(1):107. https://doi.org/10.1186/s12957-020-01882-z.

16. Xu KY, Gao H, Lian ZJ, Ding L, Li M, Gu J. Clinical analysis of Krukenberg tumours in patients with colorectal cancer-a review of 57 cases. World Surg Oncol. 2017;15(1):25. https://doi.org/10.1186/s12957-016-1087-y.

17. Jacquet $\mathrm{P}$, Sugarbaker $\mathrm{PH}$. Clinical research methodologies in diagnosis and staging of patients with peritoneal carcinomatosis. Cancer Treat Res. 1996; 82:359-74. https://doi.org/10.1007/978-1-4613-1247-5_23.

18. Al-Busaidi IS, Bailey T, Dobbs B, Eglinton TW, Wakeman CJ, Frizelle FA. Complete resection of colorectal cancer with ovarian metastases combined with chemotherapy is associated with improved survival. ANZ J Surg. 2019; 89(9):1091-6. https://doi.org/10.1111/ans.14930.

19. van Leeuwen BL. Neoadjuvant chemotherapy followed by cytoreductive surgery and hyperthermic intraperitoneal chemotherapy for colorectal cancer: a feasibility and safety study. World Journal of Surgical Oncology. 2019;17.

20. Fuzun M. Treatment of intraoperatively detected peritoneal carcinomatosis of colorectal origin with cytoreductive surgery and intraperitoneal chemotherapy. World Journal of Surgical Oncology. 2018;16:70.

21. Mrad K, Morice $P$, Fabre A, Pautier $P$, Lhommé $C$, Duvillard $P$, et al. Krukenberg tumor: a clinico-pathological study of 15 cases. Ann Pathol. 2000;20(3):202-6.

22. Kuijpers A, Mehta A, Aalbers A, van Driel W, Boot H, Verwaal V. Treatment of ovarian metastases of colorectal and appendiceal carcinoma in the era of cytoreductive surgery and hyperthermic intraperitoneal chemotherapy. Eur J Surg Oncol. 2014;40(8):937-42. https://doi.org/10.1016/j.ejso.2014.02.238.

23. Di Giorgio A, De laco P, De Simone M, Garofalo A, Scambia G, Pinna AD, et al. Cytoreduction (peritonectomy procedures) combined with hyperthermic intraperitoneal chemotherapy (HIPEC) in advanced ovarian cancer: retrospective Italian multicenter observational study of 511 cases. Ann Surg Oncol. 2017;24(4):914-22. https://doi.org/10.1245/s10434-016-5686-1.

24. Elias D, Honore C, Dumont F, Ducreux M, Boige V, Malka D, et al. Results of systematic second-look surgery plus HIPEC in asymptomatic patients presenting a high risk of developing colorectal peritoneal carcinomatosis. Ann Surg. 2011;254(2):289-93. https://doi.org/10.1097/SLA.0b013e31822638f6.

25. Jimenez W, Sardi A, Nieroda C, Sittig M, Milovanov V, Nunez M, et al. Predictive and prognostic survival factors in peritoneal carcinomatosis from appendiceal cancer after cytoreductive surgery with hyperthermic intraperitoneal chemotherapy. Ann Surg Oncol. 2014;21(13):4218-25. https:// doi.org/10.1245/s10434-014-3869-1.

26. Kim DW, Park DG, Song S, Jee YS. Cytoreductive surgery and hyperthermic intraperitoneal chemotherapy as treatment options for peritoneal metastasis of advanced gastric cancer. Journal of Gastric Cancer. 2018;18(3):296-304. https://doi.org/10.5230/jgc.2018.18.e32.

27. Lieu CH, Lambert LA, Wolff RA, Eng C, Zhang N, Wen S, et al. Systemic chemotherapy and surgical cytoreduction for poorly differentiated and signet ring cell adenocarcinomas of the appendix. Ann Oncol. 2012;23(3): 652-8. https://doi.org/10.1093/annonc/mdr279.

28. Solomon D, De Nicola N, Feingold D, Liu PH, Aycart S, Golas BJ, et al. Signet ring cell features with peritoneal carcinomatosis in patients undergoing cytoreductive surgery and hyperthermic intraperitoneal chemotherapy are associated with poor overall survival. J Surg Oncol. 2019.

29. Kuo YT, Tsai WS, Hung HY, Hsieh PS, Chiang SF, Lai CC, et al. Prognostic value of regional lymph node involvement in patients with metastatic colorectal cancer: palliative versus curative resection. World J Surg Oncol. 2021:19(1):150. https://doi.org/10.1186/s12957-021-02260-z

30. Rocca WA, Gazzuola Rocca L, Smith CY, Grossardt BR, Faubion SS, Shuster LT, et al. Bilateral oophorectomy and accelerated aging: cause or effect? J Gerontol A Biol Sci Med Sci. 2017;72(9):1213-7. https://doi.org/10.1093/ gerona/glx026.

31. Fogle RH, Stanczyk FZ, Zhang X, Paulson RJ. Ovarian androgen production in postmenopausal women. J Clin Endocrinol Metab. 2007;92(8):3040-3. https://doi.org/10.1210/jc.2007-0581. 
32. Rocca WA, Grossardt BR, de Andrade M, Malkasian GD, Melton $L$ 3rd. Survival patterns after oophorectomy in premenopausal women: a population-based cohort study. Lancet Oncol. 2006;7(10):821-8. https://doi. org/10.1016/S1470-2045(06)70869-5.

33. Rocca WA, Gazzuola Rocca L, Smith CY, Grossardt BR, Faubion SS, Shuster LT, et al. Cohort profile: the Mayo Clinic cohort study of oophorectomy and aging-2 (MOA-2) in Olmsted County, Minnesota (USA). BMJ Open. 2017; 7(11):e018861. https://doi.org/10.1136/bmjopen-2017-018861.

34. Cashin PH, Graf W, Nygren P, Mahteme H. Patient selection for cytoreductive surgery in colorectal peritoneal carcinomatosis using serum tumor markers: an observational cohort study. Ann Surg. 2012;256(6):107883. https://doi.org/10.1097/SLA.0b013e318254f281.

35. Chua TC, Morris DL, Esquivel J. Impact of the peritoneal surface disease severity score on survival in patients with colorectal cancer peritoneal carcinomatosis undergoing complete cytoreduction and hyperthermic intraperitoneal chemotherapy. Ann Surg Oncol. 2010;17(5):1330-6. https:// doi.org/10.1245/s10434-009-0866-X.

36. Simkens GA, van Oudheusden TR, Nieboer D, Steyerberg EW, Rutten HJ, Luyer MD, et al. Development of a prognostic nomogram for patients with peritoneally metastasized colorectal cancer treated with cytoreductive surgery and HIPEC. Ann Surg Oncol. 2016;23(13):4214-21. https://doi.org/1 0.1245/s10434-016-5211-6.

37. Demey K, Wolthuis A, de Buck van Overstraeten A, Fieuws S, Vandecaveye $V$, Van Cutsem $E$, et al. External validation of the prognostic nomogram (COMPASS) for patients with peritoneal carcinomatosis of colorectal cancer. Ann Surg Oncol. 2017;24(12):3604-8. https://doi.org/10.1245/s10434-0176042-9.

\section{Publisher's Note}

Springer Nature remains neutral with regard to jurisdictional claims in published maps and institutional affiliations.

Ready to submit your research? Choose BMC and benefit from:

- fast, convenient online submission

- thorough peer review by experienced researchers in your field

- rapid publication on acceptance

- support for research data, including large and complex data types

- gold Open Access which fosters wider collaboration and increased citations

- maximum visibility for your research: over $100 \mathrm{M}$ website views per year

At BMC, research is always in progress.

Learn more biomedcentral.com/submissions 